\title{
Engaging with the Enemy: \\ China-Taiwan Economic and Strategic Relations After 2008 and Beyond
}

\author{
BARTHÉLÉMY COURMONT*
}

The improvement of the China-Taiwan relationship since 2008 reshapes not only the economic ties between Taipei and Beijing but also the security dialogue over the Taiwan Strait. A new economic framework agreement (ECFA), multiple exchanges and high level meetings have characterized the re-engagement between two traditional enemies. In parallel, the development of a "Taiwanese" nationalism, that is slowly replacing the traditional " $\mathrm{Chi}$ nese" nationalism that deeply changes the nature of the relation, as well as its finality, has been observed. This article explores the current Cross-Strait relation-ship. Instead of focusing on the possibility of a reunification, it suggests that deepening economic and cultural cooperation might boost confidence that will implement possible peace agreement in a longer term.

Keywords: China, Taiwan, ECFA, Cross-Strait Relations, Security, Economy, Trade Exchanges 


\section{INTRODUCTION}

The Cross-Strait relationship between China and Taiwan is still regarded by many observers as particularly sensitive, mostly for security reasons. An approximate number of 1.400 ballistic missiles deployed in the Chinese Fujian province are still targeting Taiwan, and with the absence of common diplomatic recognition and several security mechanisms (from the Taiwan Relation Act to the Anti-secession Law), the risks of conflict remain extremely high. Alongside the North Korean peninsula dispute, the separation between Beijing and Taipei is potentially the biggest security challenge in East Asia, and the situation has remained largely unchanged since the 1949 separation between Mainland China and what Beijing still considers the "rebel province." This security "knot" is the combination of historical, ideological and cultural disputes, and has nourished a renewed nationalist discourse on both sides of the Strait (Buruma 1996; Ross 2002).

In Mainland China, the confrontation with Taiwan, although it remains hypothetical, has been used in the past two decades as an argument for a subsequent modernization of the armed forces, notably the navy (Fisher 2010). In Taiwan, the perception of the Mainland China's threat has a direct and permanent impact on the elections as well as the political debates (Wang and Chang 2006). Over the past two decades, with the exception of a quite unlikely spontaneous military invasion, the destabilizing element in the relationship between Beijing and Taipei has been a hypothetical declaration of independence of Taiwan that the Mainland authorities could use to justify military escalation, according to the 2005 anti-secession law (Cole 2006; Tsang 2006).

The Cross-Strait relationship has significantly improved in the past five years, beginning with the 2008 first election of Ma Ying-jiou to the presidency of the Republic of China (Taiwan), and the implementation of various agreements and bilateral talks, mostly in order to strengthen the economic and trade ties. The possibility of a comprehensive dialogue that includes peace talks, which used to be impossible until recently, now seems a serious option, and Ma himself announced prior to his re-election that it could take place within ten years if relations keep on improving. For the first time since 1949, peace 
has been reintroduced in the close, although still complicated, Cross-Strait dialogue. Oppositions to an increase of Cross-Strait relations remain important in Taiwan, mostly due to the reluctance in dealing with the Chinese authoritarian regime, but also considering the major gap between the two sides of the Strait, as a result of more than sixty years of separation, and completely different development, economic, social and political models. On the other side, considering that a confrontation is more than unlikely, regarding the economic interdependence, a more comprehensive Cross-Strait dialogue seems to be the only relevant option.

Based on Taiwan's trajectory and the new approach characterized by the spectacular economic reforms adopted since 2008, this article explores current Cross-Strait relations, its spectacular evolution in the past few years, its challenges and limits. Instead of focusing on the possibility of a reunification, which remains extremely premature if not impossible, it suggests that deepening economic and cultural cooperation might boost confidence that will implement possible peace agreement in a longer term. Praised by some and criticized by others, the new paradigm introduced in 2008 is based on a tacit agreement that neither the independence nor the reunification is considered a relevant option in the short term. In other words, Beijing preserves a status-quo that guarantees a de facto independent status for Taiwan, while Taipei accepts not to cross the Rubicon by officially declaring its independence. Although several obstacles remain in the establishment of a comprehensive Cross-Strait dialogue, notably on the security issues, this example of how to reshape what appeared to be an unsolvable status proves its relevancy in order to engage a new and durable partnership. It also means that the two sides of the Strait can engage in a dialogue that clearly identifies and excludes the sensitive issues, such as the sovereignty. But it does not provide definite answers to the questions related to the future status of Taiwan, as well as the permanence of the Chinese threat. The current relation appears therefore to be a transition, but no agenda seems to be satisfactory for both sides in order to define what should be the next step.

\section{THE EVOLUTION OF TAIWANESE NATIONALISM AND ITS IMPACT ON THE CROSS-STRAIT RELATIONSHIP}

To understand the trajectory of China and Taiwan since 1949 and the 
difficulty of establishing a comprehensive security dialogue, one must consider the evolution of two different models, and its impact on the perception of the Cross-Strait relations. More than six decades of separation between Taiwan and China have, with no surprise, generated major social and political differences, but also transformed the nationalist discourse over the Taiwan Strait. In Taiwan, after being based on ideological and political divergences, the arguments in favor of a separation have been in the past two decades focusing on strong identity differences, and have resulted in different evolutions of nationalism on both sides of the Strait (Chu 2004; Rigger 2007). Although it is well known that the economic and social changes have been spectacular in China since the 1980's, it is in Taiwan, through the process of democratization and "Taiwanization," that the public perception of a Taiwanese identity has evolved the most dramatically, with a direct effect on the Cross-Strait relations. The current Republic of China and its population do not have much in common with what Taiwan was in 1949 or even in the early 1990's (Roberge and Lee 2009; Muyard 2012).

During the years following the exile of 1949, Chiang Kai-shek's party regarded Taiwan as a base from where re-conquest of the continent would be possible, believing the communist regime would not last more than a few years. The KMT's nationalism was therefore based on the idea that Taiwan was the "real China," while the Mainland was led by an illegitimate government (Chi Kim and $\mathrm{Wu}$ 1992). It was only toward the end of his life that Chiang gradually discovered the meaning of being a Taiwanese president, after realizing that his dreams of re-conquest were impossible, especially in 1964 with the first Chinese nuclear test, and after 1971 with Beijing's return to the circle of nations. But for years, he claimed the principle of a momentary strategic retreat to Taiwan, notably in the 1950s, when the modernization of the armed forces was justified by the strategic plans to recover the complete Chinese territory.

In its constant ideological opposition to Beijing, the KMT nationalism claimed the defense of a Chinese orthodoxy, according to the Confucian tradition, but also based on three founding principles: On the one hand, it carried the Chinese culture, or daotong (cultural orthodoxy), in contrast with Mainland China and Mao's catastrophic reforms and attempts to eliminate the 
references to the past, from the Great Leap Forward to the Cultural Revolution (Brown 2004). On the other hand, Chiang claimed a political legitimacy, because the KMT was the leading party after the elections of 1947, while the Communists took power at the end of the civil war two years later, and without a democratic process. The KMT therefore claimed the defense of fatong (legitimate succession), which gave legitimacy to the Taiwanese authorities to regain power on the continent. Lastly, this nationalism was ideological, with the Taiwanese authorities constantly reminding everyone of their commitment to the "free world," while China was depicted as an authoritarian dictatorship. The Cold War was therefore the best ally of the KMT in its distinction with the Mainland, and its legitimacy in the eyes of the Western countries, particularly its main supporter, the United States (Dreyer 2003). In this prospect, the history of Taiwan under Chiang's "white terror" is quite similar to the trajectory of South Korea in the 1960's, under Park's leadership, and took a completely opposite trajectory to Beijing's economic, social and political reforms (Chi et al. 1992).

The prestige of Taiwan on the international scene was greatly affected in 1971, with the loss of a permanent seat on the UN Security Council, in favor of Beijing. Taipei had inherited the seat of China in 1949, but under pressure from several UN members, including developing countries, the most populous country in the world finally got its diplomatic revenge two decades later. The establishment of official relations between Washington and Beijing in 1979 and the rapprochement between the Western countries and Communist China were also perceived as a significant loss of influence and a failure for the KMT nationalism.

In its relations with Mainland China, however, the most important transformation took place in the 1990s, when Beijing started focusing on the defense of the Chinese culture, joining the arguments traditionally used by the KMT, and reducing at the same time the credibility of the defense of the three founding principles in Taiwan. This late restoration of Chinese traditions on the continent had the effect of bringing the Communists and the KMT closer in a cultural sense, but also totally delegitimized the Taiwanese traditional nationalist discourse, which had to find other arguments to remain, at the risk of losing its raison d'être (Courmont 2011). 
The Chinese nationalism imposed in Taiwan weakened after the end of the Cold War and has been disputed by the democratization process (Cooper 1988). At the same time, some studies demonstrated that even ethnically speaking, the Taiwanese may not be considered Chinese (Shi 1980; Wang 1993; Rubinstein 1999). The history of the island, based for over forty years on its references on the Chinese identity was severely affected, and the "Creole nationalism" was supported by slogans highlighting the existence of a Taiwanese culture distinct from Mainland China (Chang 1996). This ethno-centric nationalism grew strongly and had a decisive impact on Taiwan's population, with a revival of the use of the Taiwanese language, the high-lighting of the minorities' cultures, and the emphasis on Taiwan's non-Chinese origins (Hsieh 2005). Gradually, alongside the improvement of the democratization process, the discourse of Chinese culture as a symbol of national representation (and thus not only limited to the island of Formosa, but inclu-ding mainland China) faded in favor of the recognition of an insular particularism (Wang and Liu 2004). The former President Lee Teng-hui (1988-2000) once compared in an interview with a Japanese author the process of democratization in Taiwan to an "indigenousation of the power" (Lee and Naka-jima 2000: 34; Lee 1999). Distinguishing itself from China by prioritizing a specific culture, history and ethnicity, the Taiwanese nationalism claimed its own existence, and refused to be confined only to the relationship with Beijing, to realize a greater ambition: the recognition of Taiwan as an independent state (Dittmer 2005; Phillips 2003).

The development of a Taiwanese nationalism has generally and unsurprisingly been strongly denounced in Beijing, where the island's independence would be considered as a provocation, or even interpreted as a declaration of war, with implications worldwide. It has been a particularly sensitive issue after 2000 and the election of a pro-independence president in Taiwan, Chen Shui-bian, leader of the Democratic Progressive Party (DPP), which ended four decades of KMT absolute political domination on the island (Campbell and Mitchell, 2001). A few weeks before the DPP historical victory, Taiwan's president Lee Tung-hui already delivered a statement in which he emphasized the need to reconsider the definition of "China," which has pitted the KMT nationalism against that of Beijing for decades, arguing, "We used to claim 
that ROC (Republic of China) is China. The leaders in Beijing have also asserted that the PRC (People's Republic of China) is China. This coincides with the formula of 'one China, different interpretations.' The PRC is not the only one that represents China. The ROC is a state, too. And the ROC was established much earlier than the PRC. Now, Beijing intends to downgrade the government, the government of the ROC, into a local government? Should we agree to Beijing's position, all the citizens of Taiwan would become stateless" (China Times 2000). This call for a clear separatism and a redefinition of Taiwan's status was echoed by the DPP's pro-independence policy, and had an important impact on the population's perception of Cross-Strait relations, to the point that even for the KMT, seeking new directions after the defeat of 2000, the reunification option had lost most of its relevancy. The nationalist party had no choice but to change its discourse on the Cross-Strait issue, and develop rhetoric based on a stronger partnership in order to improve Taiwan's economic development and maintain at the same time the status-quo, announcing what will later be Ma's reforms.

\section{ECONOMIC RELATIONS AS AN ALTERNATIVE TO INDEPENDENCE AND REUNIFICAITON}

Since the early 1990's, the implementation of solid economic and trade Cross-Strait relations has been seen as an opportunity to reduce the risks of conflict. As a result, while pursuing two different strategies and looking for different, if not opposite objectives (reunification and independence), the different actors of the Taiwan-China dialogue have constantly promoted, more or less officially, an increase of the economic links. Behind the political discourse, and aware of the economic promises offered by a fast-growing China, both the KMT and the DPP have been in favor of developing a stronger economic partnership with Beijing, as an alternative to the highly risky (and somehow politically impossible) choice of either pushing Taiwan towards independence or engaging a process of reunification. This more pragmatic approach of the Cross-Strait relation has had the double effect of deepening the links and paving the way for the important reforms that were adopted after 2008, and reducing the political margin given to Taiwan's leaders. 
However, the DPP leadership years have had the effect of freezing an already weak dialogue, and enhanced (at least at the rhetorical level) the risks of a military confrontation in the Taiwan Strait. Mainland China pursued a dual policy by reaffirming its posture regarding Taiwan's status on one hand, while advocating a stronger dialogue with the KMT on the other (Chen 2003). On March 14, 2005, the Chinese parliament passed an "anti-secession law" that would allow Beijing to "make use of non-peaceful means" against Taiwan if the island authorities were deciding to declare independence (Wuthnow 2006). This posture immediately raised international concern on the Taiwan Strait issue, many observers fearing the risk of a future military confrontation (Cole 2006; Hao 2006; Tsang 2006; Wuthnow 2006). This crisis has, however, been accompanied in the following weeks by a spectacular rapprochement between the Chinese Communist Party and the KMT, focusing on reconciliation and common cultural values. The former vice president Lien Chan, one of the charismatic leaders of the KMT, traveled to Beijing in May 2005 to discuss a new and comprehensive relationship between the two Chinas. This visit was unofficial, however, since it was not supported by the Taiwanese government, but was nonetheless welcomed by a majority of parliament members (Bush 2006; Saunders and Kastner 2009). This trend has obviously strengthened with the landslide election of the KMT candidate Ma Ying-jiou in the 2008 presidential election, although it must be pointed out that Ma stated during the campaign that there would be no pursuit of de jure independence, no negotiations with the mainland about unification, and no use of force (Ma 2008).

Tensions remain however very strong between the two sides of the Strait. The adoption of the anti-secession law and Beijing's multiple statements on a possible military confrontation in the case of a declaration of independence are perceived as an unacceptable intrusion into Taiwan's domestic affairs (Wang and Chang 2006). While announcing an increase in the Chinese defense budget in March 2007, Jiang Enzhu, spokesman for the National People's Congress, mentioned for instance the case of Taiwan, noting that Beijing would neither tolerate any secession of the island, nor allow anyone to assist Taiwan in this regard. Reacting to this announcement, Taipei immediately sounded the alarm: "The figures illustrate the growing Chinese threat on Taiwan," Liu Teh-hsun, spokesman for the Mainland Affairs Council, stated in 
response to Beijing's posture.

As a paradox of the Cross-Strait relations, trade exchanges have in contrast significantly and constantly risen over the past decade, to reach a level of nearly US\$70 billion, while China became the third largest exporter to Taiwan under DPP leadership. This situation invited the governments of both sides to resolve their political differences and adopt a more pragmatic posture, even at the most critical times (Hao 2006). As early as in 2002, while the Chen Shui-bian administration was in place, Taiwan exports and imports increased considerably (particularly the exports), thanks largely to Cross-Strait trade, and the level of exchanges never ceased to increase since. The following table indicates the constant evolution of the Cross-Strait trade exchanges.

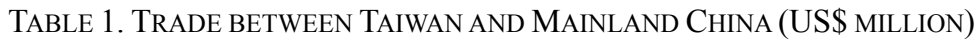

\begin{tabular}{ccccccc}
\hline \multicolumn{3}{c}{ Mainland China Customs Statistics } & \multicolumn{3}{c}{ Taiwan Customs Statistics } \\
& Exports & Imports & Total & Exports & Imports & Total \\
\hline $1990-1993$ & 17.4 & $2,055.8$ & $2,073.2$ & $24,708.1$ & $3,074.3$ & $27,782.4$ \\
1994 & 131.6 & $1,858.7$ & $1,990.3$ & $14,084.8$ & $2,242.2$ & $16,327.0$ \\
1995 & 376.6 & $3,091.3$ & $3,467.9$ & $14,783.9$ & $3,098.1$ & $17,882.0$ \\
1996 & 623.4 & $3,059.9$ & $3,683.2$ & $16,182.2$ & $2,802.7$ & $18,984.9$ \\
1997 & 626.5 & $3,915.3$ & $4,541.8$ & $16,441.7$ & $3,396.5$ & $19,838.2$ \\
1998 & 914.9 & $4,113.9$ & $5,028.8$ & $16,629.6$ & $3,869.6$ & $20,499.2$ \\
1999 & $2,602.1$ & $4,528.9$ & $7,131.0$ & $19,537.5$ & $3,951.7$ & $23,489.2$ \\
2000 & $4,391.5$ & $6,229.3$ & $10,620.8$ & $25,497.1$ & $4,994.9$ & $30,492.1$ \\
2001 & $4,895.4$ & $5,903.0$ & $10,798.3$ & $27,339.5$ & $5,000.2$ & $32,339.7$ \\
2002 & $10,526.9$ & $7,968.6$ & $18,495.5$ & $38,063.1$ & $6,585.9$ & $44,649.0$ \\
2003 & $22,890.8$ & $11,017.9$ & $33,908.6$ & $49,362.3$ & $9,004.7$ & $58,367.0$ \\
2004 & $36,349.4$ & $16,792.3$ & $53,141.6$ & $64,778.6$ & $13,545.2$ & $78,323.8$ \\
2005 & $43,643.7$ & $20,093.7$ & $63,737.4$ & $74,684.4$ & $16,549.6$ & $91,234.0$ \\
2006 & $51,808.6$ & $24,783.1$ & $76,591.6$ & $87,109.0$ & $20,735.2$ & $107,844.2$ \\
2007 & $62,416.8$ & $28,015.0$ & $90,431.7$ & $101,021.7$ & $23,458.3$ & $124,480.0$ \\
2008 & $66,883.5$ & $31,391.3$ & $98,274.8$ & $103,339.6$ & $25,877.9$ & $129,217.5$ \\
2009 & $54,248.7$ & $24,423.5$ & $78,672.2$ & $85,722.9$ & $20,505.3$ & $106,228.2$ \\
2010 & $76,935.1$ & $35,946.0$ & $112,881.1$ & $115,693.9$ & $29,676.6$ & $145,370.5$ \\
2011 & $83,960.0$ & $43,596.5$ & $127,556.5$ & $124,919.9$ & $35,111.9$ & $160,031.8$ \\
2012 & $80,714.2$ & $40,908.2$ & $121,622.5$ & $132,183.9$ & $36,779.1$ & $168,963.0$ \\
\hline
\end{tabular}

NOTE: Exports indicates the amount of exportation from Taiwan to Mainland China, and Imports indicates the amount of importation from Mainland China to Taiwan.

SOURCE: Mainland Affairs Council, Cross-Strait Economic Statistics Monthly, May 2013, http://www.mac.gov.tw/public/Attachment/343011464625.pdf. 
These figures indicate that even in times of complete lack of dialogue, Taiwan and China have increased their economic interdependency. This situation most certainly had a big impact on President Ma Ying-jiou's decision to implement a new economic and cultural dialogue. It also indicates the existence of a consensus among the Taiwanese political leaders regarding a distinction between the difficult political relation and the absence of a security framework on one side, and the improvement of economic ties to the benefit of Both Taipei and Beijing on the other. Last, it shows the lack of options offered to the Taiwanese leaders in the reaffirmation of a new relation with Beijing. Considering the attractiveness of the Chinese economy, both the KMT and the DPP slowly acknowledged the necessity of engaging with Beijing in the economic sector to revive the domestic growth and benefit from the Chinese dynamic. After experiencing both the power and the opposition, and behind the slogans, the biggest-if not the only-difference between Taiwan's two biggest political parties as regards the Cross-Strait relations lies therefore in the identification of the level of this engagement and the guarantees, if necessary, that should be implemented in order to secure Taiwan's sovereignty in the long term. For the KMT, which has abandoned its Chinese nationalist discourse after the 2000 defeat, the economic rapprochement with Mainland China must be official, and extended to all spheres with the exception-at least in the short term-of the political issues. For the DPP, which has slowly moved from an independent posture to the preservation of the sovereignty, this engagement raises the risk of economic dependence, and will ultimately have an impact on Taiwan's political margin. This difference, instead of a deep divergence, explains the volatility of the public opinion on the economic engagement with Mainland China.

\section{MA'S REVOLUTION IN THE CROSS-STRAIT RELATIONSHIP}

Since he became Taiwan president after the March 22, 2008 election, after a campaign mainly focused on the economic programs, Ma Ying-jiou has revived the possibility of normalizing relations with Beijing and implementing a comprehensive dialogue between the two rival entities (Saunders and Kastner, 2009). After a series of historical and highly symbolic agreements with regard 
to direct flights and cultural exchanges, the most spectacular initiative has been the signing in 2010 of the Economic Cooperation Framework Agreement (ECFA), which formalizes the economic interdependence, and is supposed to boost Taiwan's economic growth. But Ma Ying-jiou still has to convince both China and a significant part of Taiwanese public opinion that reconciliation is possible without compromising Taiwan's sovereignty (Seidman 2011). In this regard, discussions on trade and the relevance of implementing a free CrossStrait trade zone are indicative of the deep divisions that remain in Taiwan on the sensitive issue of the relation with Beijing (Lo and Tsaur 2010, 170).

The biggest challenge for the Taiwanese authorities seems however not to implement a new partnership with Beijing, but to convince a still reluctant Taiwanese population of its necessity. The Mainland Affairs Council (MAC) conducted late 2009, half way between Ma's election and the implementation of ECFA, a public opinion survey to evaluate the Taiwan people's views on Cross-Strait relations. Its results indicate that 65.3 percent of the public support the signing of a Cross-Strait Agreement on Cooperation in Respect of Standards, Metrology, Inspection and Accreditation. Also, 61.3 percent think that the signing of a cross-Strait Agreement on Cooperation of Agricultural Product Quarantine and Inspection would be conducive to protecting the people's health. Furthermore, 56 percent of the people approve of the signing of a cross-Strait Agreement on the Avoidance of Double Taxation, while 50 percent support the signing of the Cross-Strait Agreement on the Cooperation in Respect of Fishing Crew Affairs (MAC, 2009). More recent statistics, also conducted by the MAC, indicate however that although the Taiwanese government still benefits from the support of the majority of the public opinion, those in favor of a "status quo now/independence later" approach have gained significantly more weight in the past three years, since the return of the KMT to the presidency, and even more significantly after the ECFA was signed. Another survey conducted in May 2011 indicates that although 46.1 percent of the people believe the pace of Cross-Strait exchanges is just right, 32.6 percent believe it is moving too fast, while only 13 percent consider it too slow (MAC, 2011a). Finally, another survey indicates that the majority of the people in Taiwan (53.6 percent) still believe that Beijing is hostile toward the Taiwanese government, while 44.7 percent believe in China's hostility toward the Tai- 
wanese population (MAC 2011b).

These various surveys not only show that the support for stronger CrossStrait relations still remains fragile, but also that the reluctance to believe China's intentions and any attempt to diminish Taiwan's sovereignty receives the support of the majority of the Taiwanese people. The situation could become even harder to manage if the signing of the ECFA is interpreted as a forerunner of Beijing's "one country, two systems." Many polls show that 70 to 80 percent of the people in Taiwan do not accept the "one country, two systems" status. Such a clear mainstream public opinion reflects the deeply held misgivings among the majority of the Taiwanese people, and according to the Taipei Economic and Cultural Office (TECO) in San Francisco, in the past 10 years, the number of people supporting unification has decreased from 29 to 14 percent, while the number supporting independence has increased from 26 to 31 percent (Taiwan Sights 2010). Ma Ying-jiou knows that he has to take these elements into account, and so will any future political leader in Taiwan, notably by addressing Cross-Strait relations under the policy of no unification, no independence and no use of force, but also by keeping all options on the table, depending on Beijing's attitude. That also concerns the DPP, as the main opposition presidential candidate during the 2012 election, Tsai Ing-wen has surprisingly said she was open to the island's unification with the mainland, providing the issue wins popular support, stating that "I do not rule out any possibility $\cdots$ as long as Taiwan people support it" (South China Morning Post 2011). Tsai's condition indicates that whatever the evolution of the CrossStrait relation will be, the Taiwanese leaders will have to respect the choices of the population. It also shows the DPP confidence in the fact that the public opinion is not likely to change its position regarding unification as a consequence of the implementation of new economic ties.

The fact is that the Taiwanese population remains uncertain regarding Taiwan's relationship with China and volatile when it comes to define themselves as Taiwanese or Chinese (Brown 2004; Cabestan 2009). In a survey conducted in June 2010, 52.4 percent of respondents considered themselves as Taiwanese, 40.4 percent as both Taiwanese and Chinese, and 3.8 percent as Chinese (Election Studies Center 2010). Although the number of people who consider themselves Taiwanese exceeds those who consider 
themselves Chinese, or both, the results indicate deep differences of perception when it comes to the identity, making Taiwan a very specific case on this particular issue.

According to an updated pool published in June 2012, only 3.6 percent of the respondents identify themselves as "Chinese" (group 1) while 53.7 percent identify themselves as "Taiwanese" (group 2). To the same question, the answers were respectively 25.5 percent and 17.6 percent in 1992 . At the same time, the number of respondents who choose to be identified as "both Chinese and Taiwanese" (group 3) dropped from 46.4 percent in 1992 to 39.6 percent in 2012 (Election Study Center, 2012). We notice in these figures a completely change of the perception. In 1992, the group 3 dominated, while the group 1 came second and the group 2 came third. Twenty years later, the group 2 is far ahead, only followed by the group 3, while the group 1 represents a very small number of respondents.

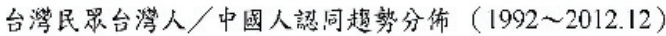

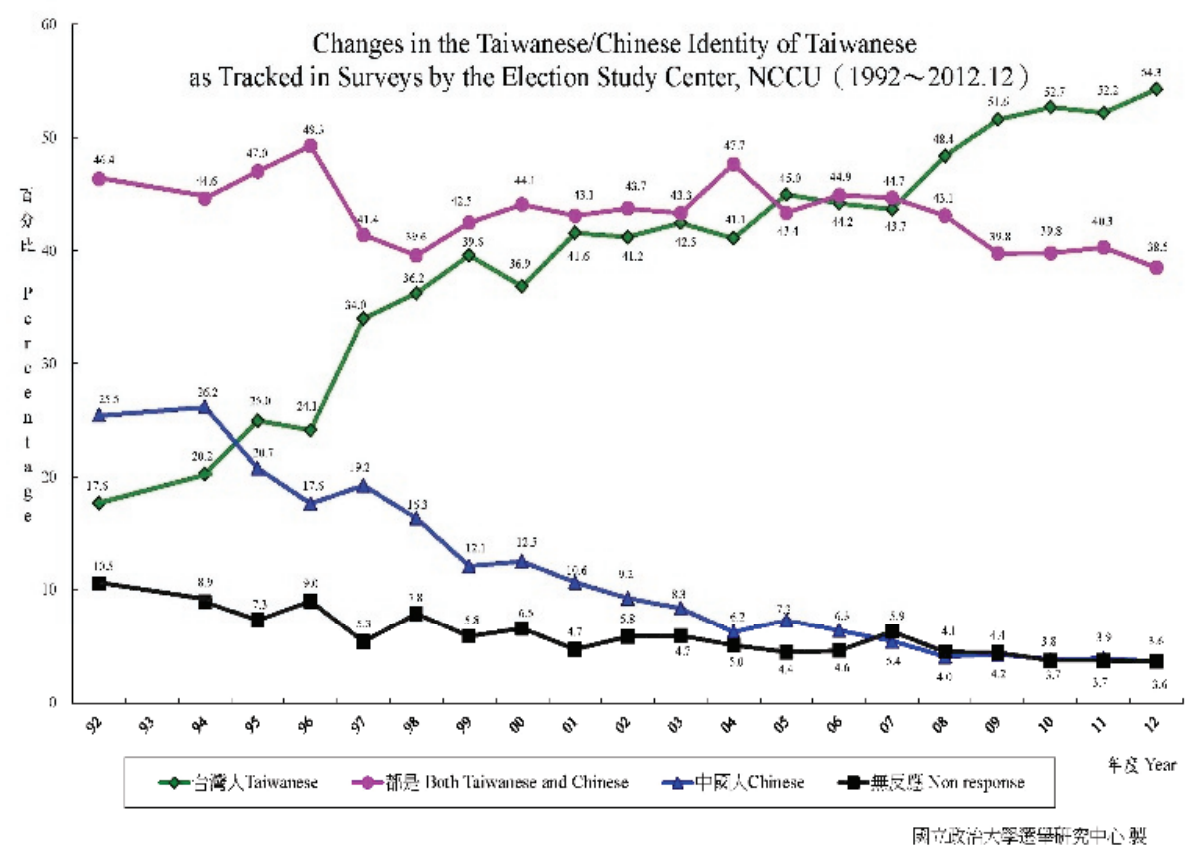

This figure illustrates the spectacular shift of the public opinion regarding the national identity in the past two decades. We may evaluate this evolution 
from different perspectives (Wang and Liu 2004), notably depending on the definition given to a "Taiwanese" identity, but also to the sense of the "both Taiwanese and Chinese" feeling. For instance, what importance, if any, do the respondents give to these two identities: at the same level or not, and if it is the case, what is the identity that would define them on top of the other. Taiwan's youth seems particularly reluctant to the current polarization. For example, individuals may want Taiwan to be an independent nation but may also want to pursue job opportunities in China (Rigger 2011). Consequently, while Taiwan's youth are deeply alienated from the current debate over national identity and Cross-Strait relations, their views and values are most relevant for resolving it, and the identification as "Taiwanese" does not automatically mean a rejection of any rapprochement with China, as it did two decades ago.

It seems however that the "Chinese" identity now reflects a minority of people who still favor the unification, and this minority is rapidly and undoubtedly diminishing. We may therefore consider that if the improvement of economic ties between Taiwan and China is overall well perceived, it does not suggest major political changes in Taiwan in favor of unification, at least as long as China has not achieved a process of democratization (Kastner and Rector 2008).

In an interview in 2007, at the time the "Taiwanese" feeling was overcoming the "both Chinese and Taiwanese" feeling, the former President Chen Shui-bian already mentioned this spectacular evolution and stated that "the rise of Taiwan-centric consciousness is reflected in the growth and decline in the number of people who see themselves, respectively, as Taiwanese and not Chinese, and as Chinese and not Taiwanese" (Chen 2007). In this prospect, Ma's reforms and their impact confirmed Chen's prediction, which has been interpreted by the DPP as the proof that ECFA is a wrong approach in CrossStrait relations (Lo and Tsaur 2010). Ma's re-election in January 2012 demonstrated however that the Taiwanese population does not reject a spectacular increase of economic ties with China, although this support may not be interpreted as a blank check for political agreements that would affect the statusquo. Ma's revolution in Cross-Strait relations may therefore be evaluated mostly at the economic level, not so much at the political one. 


\section{BEYOND THE ECONOMIC DIALOGUE AND THE ECFA IN THE LONG TERM}

In the long term, Taiwan's decision to sign the ECFA can be seen as an important choice driven by economic growth and inclusion, considering that Taiwan's economic position could well deteriorate if it is excluded from the rapidly growing number of Free Trade Agreements (FTAs) in East Asia. Since 2010, Taipei has launched FTA talks with Singapore and New Zealand, and most of Taiwan's trading partners have upgraded their "unofficial official" relationship with Taiwan without encountering objections from Beijing. By the end of 2012, 124 countries and territories, including the United Kingdom, Japan, Canada, the European Union and the United States, have offered Taiwan citizens visa-free travel status. Taiwan has also expanded its economic ties with important emerging market countries, such as India in 2012 (Chu 2013). The Cross-Strait trade liberalization may potentially have significant positive impacts on exports and GDP growth for both Taiwan and China and on the other side Taiwan would face significant economic losses if it is excluded from East Asians FTAs in which China participates (Clark 2011, 8).

During Ma's first term, China's Association for Relations Across the Taiwan Strait (ARATS) and Taiwan's Straits Exchange Foundation (SEF)-the two semi-official agencies respectively founded in 1991 and 1990 to handle Cross-Strait negotiations, and officially mandated to sign the ECFA-have sealed 16 agreements covering intellectual property rights, investment protection, customs co-operation, mutual judicial assistance and a host of other areas (Chu, 2013). The responses to the international economic crisis have had the effect of boosting the economic dialogue between Taipei and Beijing. As the Taiwanese expert Chu Yun-han notices, "the intensified economic ties enhanced the spillover effect of China's RMB 4 trillion (US\$650 billion) economic stimulus package, which generated some timely purchase orders for a range of Taiwanese manufacturers, pulling them back from the brink of bankruptcy" (Chu 2013).

Taiwan's service sector has benefited significantly from mainland Chinese tourists, whose number is expected to top 2.3 million in 2013, up from just 300,000 in 2008, when the first direct flights were implemented. Those tourists 
are giving a much-needed boost to Taiwan's economy, according to a report issued by Barclays Bank. Despite a 0.2 percent contraction in the economy during the second quarter of 2012 because of falling exports, unemployment was near a four-year low by the end of the year. That job creation is largely because of growing demand for retail and travel-related services. Nearly half of the net 77,600 jobs created in the first half of 2012 were in hotels, restaurants and retail outlets (Mishkin 2012).

Ma's trade and economic engagement with China has been approved by a significant majority of Taiwanese, who had the opportunity to elect him for a second term in January 2012. Although Ma's victory was not as large as in 2008, his opponent Tsai Ing-wen did not manage to convince the voters that the opposition party, the DPP, has a viable alternative to the new economic ties with Mainland China. As a matter of facts, the DPP candidate did not criticize the implementation of a new relation with Beijing during the campaign, focusing instead on the orientations taken by this relation, and the long-term consequences of a growing economic dependence toward China. Tsai abandoned the identity motif and stressed economic issues. As the Taiwanese expert $\mathrm{Wu}$ Yu-shan notices, "she calculated that deep-Green identity voters would vote for her anyway, and the party's new stance on socio-economic issues would win her those dissatisfied with Ma's performance" (Wu 2013). Her defeat in the presidential election reinforced Ma's credit among those who believe that ECFA is the only possible option, but it did change the nature of Taiwan politics at the same time, after several years of turbulences. Does that mean that the future of Taiwan politics will be exclusively focusing on the economy, while the identity debate will slowly fade? Probably not, but the case for independence alone might not be consistent enough to attract new voters, and the 2012 presidential election therefore seems to close a chapter of Taiwan politics that followed the adoption of ECFA in 2010.

During the weeks the weeks that preceded the signature of the agreement and its implementation, several protests have been organized to oppose what was seen as a potential compromise on Taiwan's sovereignty. The opposition between the pro-ECFA and the opponents to the agreement turned political as an incident took place at the Legislative Yuan (Taiwan's Parliament) on July 8, 2010. The DPP insisted during this meeting the ECFA agreement be reviewed 
article by article. That demand was rejected by the KMT caucus (Taipei Times 2010). A fight then broke out among the legislators, and the KMT accused the then DPP Chairman Tsai Ing-wen for the incident (Taiwan News 2010).

While the Ma administration has been trying to deal with opposition criticism and maintain public support for the cautious steps it is taking on economic issues, Beijing has urged Taipei to begin addressing political issues. Beijing's interest appears to reflect Hu Jintao's initial instructions to begin laying the groundwork for political talks. Ma has resisted this pressure, and has stated several times that the time is not ripe for political talks. Presumably, Taipei has been assuming that such statements are necessary to address opposition suspicions that Ma has a secret unification agenda (Brown 2010, 3). The problem however lies in whether the political talks are considered an ultimate goal in the implementation of trade and economic ties with China, and how long can the Taiwan president resist the pressures from Beijing on one side, the Taiwanese population in its majority on the other.

The Taiwanese president believes however that the reforms that started in 2008 can potentially lead to a deep transformation of the Cross-Strait relation. Interviewed on the meaning of his "Golden decade" plan, adopted in June 2012 and integrated within the development program for the period 2013-2016, Ma Ying-Jiou considers that "a dynamic economy, a fair society, a transparent government, a competitive education system, a preserved environment, a global development, solidarity links with the entire world: these are, with the implementation of a durable peace between the two sides of the Strait, the pillars on which we will build the "golden decade" (Ma 2012, 303). This "durable peace" may be interpreted in different manners, and the question remains whether it must be implemented through mechanisms, or simply by increasing the economic interdependency. The question whether Beijing and Taipei apprehend this "durable peace" in the same sense also remains highly uncertain, and may have a considerable impact on the future of the Cross-Strait relations and the possibility to engage talks on security and political issues.

Through ECFA, China mostly extends World Trade Organization (WTO) -standard most-favored nation status to Taiwan-meaning trade terms equivalent to those all other WTO members receive-while Taiwan imposes unilateral barriers to imports, investment, and visitors from China. Economically spea- 
king, however, the more "protected" party-Taiwan-saddles its household consumers and enterprise manufacturers with more expensive inputs where China would be most competitive, deprives the economy of productive investment, and cuts off skilled labor mobility that could benefit Taiwan (Rosen and Zhi 2010). Ultimately, it is well known that China supports ECFA because it believes this will maximize the prospect for eventual political integration across the Taiwan Strait. But officials in Beijing argue that this belief is rooted not in the idea that ECFA would enhance their ability to coerce Taiwan but in the view that it would maximize mutual prosperity and Taiwan's perception of common interest, thereby establishing the goodwill necessary to facilitate political rapprochement in the future (Rosen and Zhi 2010,2). This official posture is the result of the calculation that any attempt to accelerate the reforms in the Cross-Strait relation could jeopardize the success of the establishment of peaceful relations. Zhang Nianchi, director of the Shanghai Institute of East Asian Studies, published in 2009 an article in Zhongguo pinglun in which he cautioned against a premature push for political negotiations, in order to cool off those in Beijing who saw in Ma's first election the promise of a political reunification in the short term. He specifically suggested that a period of "peaceful development" in Cross-Strait relations represents a long and unavoidable transitional stage toward peaceful unification, and advised that Cross-Strait relations must respect the reality and focus on noncontroversial issues (Zhang 2009). It explains why, throughout Ma's first term, Beijing chose to go along with Taipei's preferred formula of "first the easy, then the hard; the economic first, then the political" (Romberg 2012), and considering Xi Jinping's profile, it is likely that this posture will remain, at least for the next few years.

The American Taiwan expert Raymond Burghardt believes that "both sides have essentially agreed to deal with the easy issues first such as trade and transportation, and leave the hard stuff such as Taiwan's international representation for later" (quoted in Roberge and Lee 2009). Several experts predict, like Burghardt, the current rapprochement will continue but will not proceed into the political realm toward unification with China or independence for Taiwan (Hsieh 2008).

However, several American observers and Ma's political opposition at 
home argue that Taiwan has been slowly "drifting into Beijing's sphere of influence" (Giley 2010). They believe that Ma's accommodating measures have effectively reduced Taiwan's political autonomy (Zhang 2011). One may therefore question that strategy, which can be explained by the necessity to distinguish the economy and the sovereignty issue, to the point that the engagement with Beijing, although uncertain and risky, seems to be calculated. Whether it is a good calculation remains, however, subject to various interpretations. It is however certain that the current situation is a transition, and that ultimately some important decisions regarding the enlargement of the current dialogue to the political sphere or the reaffirmation of Taiwan's sovereignty will have to be taken. And when these times come, the Taiwanese president will have to make sure that his decision, whatever direction it takes, will have the support of the population.

\section{CONCLUSION}

The case of Taiwan-China relation since 2008 is particularly interesting in many aspects regarding the changing nature of the dialogue between two historic rivals, the evolution of Taiwan politics, the perspective on untying the knot, and giving Taiwan an opportunity to engage economic ties, and furthermore, with other actors, in Asia in particular. Although not new, the process of normalization of Cross-Strait relations does not suggest, at least in the short term, any dialogue on unification (Cabestan 1996; Brown 2010; Clark 2011; Seidman 2011; Vio 2012). It ultimately poses however the question of the future evolution of the relation between the two entities at the security and political level, and whether both sides of the Strait may identify converging goals, which seems at the moment extremely unlikely.

So far, the intensification of exchanges, without any peace agreement, nor any agenda that suggests that negotiations will be reaching the security level, has been exclusively focused on a confidence building based on closer economic ties, and a tacit although unofficial agreement that the security issues remain unchanged. However, as the American experts Philipp C. Saunders and Scott L. Kastner state, "although a peace agreement would not end the risk of war across the Taiwan Strait, such an agreement would likely be more 
effective than mutual restraint. An explicit peace agreement could produce additional benefits that help to sustain cooperation, include mechanisms that make it harder for either side to walk away, and be more durable over time and across changes in political leadership" (Saunders and Kastner 2009, 99). Such an evolution although it may indeed produce additional benefits, remains quite unlikely if not impossible, considering the reluctance in the Taiwanese population to move further in the direction of an explicit peace agreement, and it will certainly take more years to define the terms of such an agreement. Nevertheless, the implementation of economic ties reduces the uncertainty between Beijing and Taipei, which potentially leads to tensions, although it does not eliminate the risk of conflict (Kastner 2006). It is therefore a significant evolution in the Cross-Strait relation, which may potentially have an impact on both sides that neither Beijing nor Taipei seem to have fully acknowledged. And considering the difficulty for the Taiwanese political leaders to receive a strong support for further moves, the economic and cultural ties appear to be the least risky of all options. It is therefore, for both parties, a transitional stage that produces benefits for both actors.

On one side, the reduction of uncertainty combined with the absence of a clear political and security agenda serves Beijing interest in the sense that Taiwan's independence goal seems adjourned, if not abandoned, as long as the economy is identified as the priority by the Taiwanese authorities. On the other side, and to some extent, several experts argue that expanding economic and social ties across the Strait will only enhance Taiwan's soft power and enable Taiwanese non-governmental organizations, mass media, academic and religious organizations to facilitate China's political and social transition (Chu 2012a). This idea is partly based on the observation that "the interest and curiosity in Taiwan's democratic process was so overwhelming among mainland Chinese netizens that Beijing's cyber-policing authority had to drop the idea of erecting a firewall against Taiwan-based news media during the 2012 presidential campaign" (Chu 2012b).

Last, the Cross-Strait relation's evolution and the new paradigm potentially caries in the long term proposals for change in East-Asia security and diplomatic links, by including the trade and economic aspects of a bilateral relation as the first step to a possible security dialogue. It may for example 
have an impact on an inter-Korean dialogue, and the implications of actors such as China and Japan. Therefore, its success will not only be evaluated on the trajectory of the Taiwan-China dialogue and the implementation of confidence building measures that will reinforce the economic ties, but also on its ability to reshape State-to-State relations in East-Asia, notably among longtime rivals and, in some cases, enemies.

\section{REFERENCES}

Brown, Melissa J. 2004. Is Taiwan Chinese? The Impact of Culture, Power, and Migration on Changing Identities (Berkeley, CA: University of California Press).

Brown, David G. 2010. China-Taiwan Relations: Moving Ahead Slowly. Comparative Connections. Available at: http://csis.org/files/pub lication/0904 qchina_taiwan.pdf.

Buruma, Ian. 1996. Taiwan's New Nationalists. Foreign Affairs 75(4): 77-91.

Bush, Richard C. 2006. Untying the Knot: Making Peace in the Taiwan Strait (Washington, D.C: Brookings Institution Press).

Cabestan, Jean-Pierre. 1996. Taiwan's Mainland Policy: Normalization, Yes; Reunification, Later, The China Quarterly 148(Special Issue): 1260-1283. Cabestan, Jean-Pierre. 2009. Taiwan: An Internal Affair! How China's Domestic Politics and Foreign Policy Interact on the Taiwan Issue?. East Asia 26(1): 1-20.

Campbell, Kurt M. and Derek J. Mitchell. 2001. Crisis in the Taiwan Strait?. Foreign Affairs 80(4).

Chang, Mau Kui. 1996. Political Transformation and the 'Ethnization' of Politics in Taiwan. in Taiwan an der Schwelle zum 21 Jahrhundert-Gesellschaftlichen Wandel, ed. Gunther Schubert and Axel Schneider (Hamburg: Institut für Asienkunde): 135-152.

Chen, Shui-bian. 2007. Washington Post Interview with President Chen Shuibian, Washington Post.

Chen, Tain-jy. 2003. Will Taiwan Be Marginalized by China?. Asian Economic Papers 2(2): 78-97.

Chi, Huang, Woosang Kim, and Samuel Wu. 1992. Conflicts across the Tai- 
wan Strait: 1951-1978. 28(6): 35-58.

China Times. 2000.

Chu, Yun-han. 1998. Taiwan's Unique Challenges, in Larry Diamond and Marc F. Platiner (ed.), Democracy in East Asia (Maryland: The Johns Hopkins University and National Endowment for Democracy): 133-147.

Chu, Yun-han. 2004. Taiwan's National Identity Politics and the Prospect of Cross-Strait Relations. Asian Survey 44(4): 484-512.

Chu, Yun-han. 2012a. Taiwan and China's Democratic Future. Journal of Democracy 23(1).

Chu, Yun-han. 2012b. Sizing Up Taiwan's Election. Global Asia 7(1).

Chu, Yun-han. 2013. Strait Forward: The Political Implications of TaiwanMainland Economic Integration. Global Asia 8(1).

Clark, Cal. 2011. The Changing Dynamics of the Relations among China, Taiwan, and the United States. in Cal Clark (ed.), The Changing Dynamics of the Relations among China, Taiwan, and the United States (Cambridge: Cambridge Scholars Publishing): 1-9.

Cole, Bernard. 2006. Taiwan's Security: History and Prospects (New York: Routledge).

Cooper, John F. 1988. A Quiet Revolution: Political Development in Republic of China (Washington D.C.: Ethic and Public Policy Center).

Courmont, Barthélémy. 2011. Sovereignty, Democracy and Identity: Domestic

Debates Over the Definition of the Nation in Taiwan, Korean Journal of Defense Analysis 23(4).

Dittmer, Lowell. 2005. Taiwan's Aim-Inhibited Quest for Identity and the China Factor. Journal of Asian and African Studies 40(1/2): 71-90.

Dpeyer, June Teufel. 2003. Taiwan's Evolving Identity. Asia Program Special Report 114: 4-10.

Election Study Center. 2010. Taiwanese/Chinese Identification Trend Distribution in Taiwan (06/1992-06/2010) (Taipei: National Chengchi University). Available at: http://esc.nccu.edu.tw/english/modules/tinyd2/content/ TaiwanChineseID.htm.

Election Study Center. 2012. Changes in the Taiwanese/Chinese Identity of Taiwanese as Tracked in Surveys by the Election Study Center (199212/2012) (Taipei: National Chengchi University). Available at: http://esc. 
nccu.edu.tw/english/modules/tinyd2/content/TaiwanChineseID.htm.

Fell, Dafydd. 2005. Party Politics in Taiwan: Party Change and the Democratic Evolution of Taiwan, 1991-2004 (New York: Routledge).

Fisher, Richard. 2010. China's Military Modernization: Building for Regional and Global Reach (Stanford: Stanford Security Studies).

Giley, Bruce. 2010. Not So Dire Straits: How the Finlandization of Taiwan Benefits US Security. Foreign Affairs 89(1): 44-60.

Hao, Zhidong. 2006. Obstacles to Cross-Strait Integration. Issues and Studies 42(1).

Hong, Tsai-Lung and Yang Chih-Hai. 2011. The Economic Cooperation Framework Agreement between China and Taiwan: Understanding Its Economics and Politics. Asian Economic Papers 10(3): 79-96.

Hsieh, John Fuh-Sheng. 2005. Ethnicity, National Identity, and Domestic Politics in Taiwan. Journal of Asian and African Studies 40(1/2): 13-28.

Hsieh, Pasha L. 2008. China-Taiwan trade relations: Implications of the WTO and Asian Regionalism. in Paul Davidson (ed.), ASEAN and APEC. Trading Arrangements in the Pacific Rim, Oxford University Press.

Kagan, Richard C. 2007. Taiwan's Statesman: Lee Teng-hui and Democracy in Asia (Annapolis, MD: Naval Institute Press).

Kastner, Scott L. 2006. Does Economic Integration across the Taiwan Strait Make Military Conflict Less Likely?. Journal of East Asian Studies 6(3): 319-346.

Kastner, Scott L. and Chad Rector. 2008. National Unification and Mistrust: Bargaining Power and the Prospects for a PRC/Taiwan Agreement. Security Studies 17(1): 39-71.

Lee, Teng-hui. 1999. Taiwan de zhuzhang (Taiwan's Request) (Taipei: Yuanliu).

Lee, Teng-hui and Nakajima Mineo. 2000. Yazhou de zhilue (The Asian Intelligence) (Taipei: Yuanliu).

Lo, Chih-cheng and TSAUR Tien-wang (ed.). 2010. Deconstructing ECFA: Challenges and Opportunities for Taiwan (Taipei: Taiwan Brain Trust Policy Series1).

Ma, Ying-jiou. 2008. A Smart Strategy for National Security. speech given at the Association for the Promotion of National Security, Republic of China. 
Ma, Ying-Jiou. 2012. interviewed by Marie Holzman, «Vers une décennie d'or », Politique internationale 138: 295-303.

Mac public opinion survey. 2009. The majority of the public support the negotiation issues of the Fourth Chiang-Chen Talks, Mac. Available at: $\mathrm{http}: / /$ www.mac.gov.tw/ct.asp?xItem $=73601 \& \mathrm{ctNode}=6256 \& \mathrm{mp}=3$

Mac public opinion survey. 2011a. The Pace of Cross-Strait Exchanges, Mac. Available at: http://www.mac.gov.tw/public/Attachment/16914254123. gif.

Mac public opinion survey. 2011b. Beijing's Hostility Toward ROC, MAC. Available at: http://www.mac.gov.tw/public/Attachment/1691426075.gif. Mishkin, Sarah. 2012. Chinese tourists boost Taiwan's economy, Washington Post.

Muyard, Frank. 2012. The Formation of Taiwan's New National Identity since the End of the 1980's. in David Blundell, Taiwan since Martial Law. Society, Culture, Politics, Economy (Berkeley, Taipei: University of California and National Taiwan University Press): 297-366.

Phillips, Steven E. 2003. Between Assimilation and Independence: The Taiwanese Encounter Nationalist China (Stanford, CA: Stanford University Press).

Rigger, Shelley. 2007. Taiwan's Rising Rationalism: Generations, Politics, and 'Taiwanese Nationalism', (Washington, D.C.: East-West Center).

Rigger, Shelley. 2011. Strawberry Jam: National Identity, Cross-Strait Relations, and Taiwan's Youth. in Cal Clark (ed.), The Changing Dynamics of the Relations among China, Taiwan, and the United States (Cambridge: Cambridge Scholars Publishing): 78-97.

Roberge, Michal and Youkyung Lee. 2009. China-Taiwan relations. Backgrounder, Council on Foreign Relations. Available at: http://www.cfr.org/ china/china-taiwan-relations/p9223.

Romberg, Allan. 2012. Cross-Strait Relations: First the Easy, Now the Hard. China Leadership Monitor 28, Hoover Institution, Stanford University.

Rosen, Daniel H. and Zhi Wang. 2010. Deepening China-Taiwan Relations through the Economic Cooperation Framework Agreement. Policy Brief, Peterson Institute for International Economics. Available at: http://www. iie.com/publications/pb/pb10-16.pdf. 
Ross, Robert S. 2002. Navigating the Taiwan Strait: Deterrence, Escalation Dominance, and U.S.-China Relations. International Security 27(2): 4885.

Rubinstein, Murray (ed.). 1999. Taiwan: A New History (Armonk, NY: M. E. Sharpe).

Saunders, Phillip C., and Scott L. Kastner. 2009. Bridge Over Troubled Water. International Security 33(4): 87-114.

Seidman, Jonathan S. 2011. In Taiwan, a Quieting Opposition to China Talks. World Politics Review.

SHI, Ming. 1980. The Four Hundred Years of Taiwanese History [in Chinese], (San Jose, CA, Pengdao wenhua gongsi).

South China Morning Post. 2011. Taiwan's Tsai states the condition for unification.

Sutter, Robert. 2011. Taiwan's Future: Narrowing Straits, NBR Special Report. Available at: http://www.nbr.org/publications/analysis/pdf/Free/02 112012/A11_Taiwan.pdf.

Taipei Times. 2010. Legislators brawl over ECFA review. Available at: http:// www.taipeitimes.com/News/front/archives/2010/07/09/2003477482.

Taiwan News. 2010. Taiwan legislature clashes mark start of ECFA review. Available at: http://www.etaiwannews.com/etn/news_content.php?id = $1313025 \&$ lang $=$ eng_news\&cate_img $=83 . j p g \&$ cate_rss $=$ news_Politics.

Taiwan Sights. 2010. Opinion poll arrives at a 'chopsticks' analogy of crossStrait relations. Available at: http://www.taiwaninsights.com/2010/09/24/ opinion-poll-arrives-at-a-chopsticks-analogy-of-cross-strait-relations/.

Tsai, Shih-Shan Henry. 2005. Lee Teng-hui and Taiwan's Quest for Identity (New York: Palgrave Macmillan).

Tsang, S. 2006. If China Attacks Taiwan: Military Strategy, Politics and Economics (New York: Routledge).

$\mathrm{Tu}$, Weiming. 1996. Cultural Identity and the Politics of Recognition in Contemporary Taiwan. The China Quarterly 148(Special Issue): 1115-1140.

Vio, Jose Guerra. 2012. Economic Integration Across the Taiwan Strait: A Case of Cultural Identity Transformation and Contested National Sovereignty in the Context of Globalization. in David Blundell, Taiwan since Martial Law. Society, Culture, Politics, Economy (Berkeley, Taipei: University of California and National Taiwan University Press): 527-548. 
Wang, T. Y. and I-chou Liu. 2004. Contending Identities in Taiwan: Implications for Cross-Strait Relations. Asian Survey 44(4): 568-590.

Wang, T. Y. Wang, and G. Andy Chang. 2006. External Threats and Political Tolerance in Taiwan. Political Research Quarterly 59(3): 377-388.

Wang, Yude. 1993. Taiwan: A Gloomy History [in Chinese], (Taipei: Zili wanbaoshe wenhua chuban bu).

Wu, Yu-shan. 2013. From Identity to Economy: Shifting Politics in Taiwan. Global Asia 8(1).

Wuthnow, Joel. 2006. The Integration of Cooptation and Coercion: China's Taiwan Strategy since 2001. East Asia 23(3): 22-45.

Zhang, Nianchi. 2009. Liang an xian jing hou zheng bu yi jizao. (Developing Cross-Strait Relations Should Adopt the Economic First, Politics Later Strategy), China Times.

Zhang, Baohui. 2011. Taiwan and China: The Honeymoon That Never Got As Far as Finland. Global Asia 6(1). 


\section{ENDNOTES}

1 The expression of "knot" has been used on several occasions to describe the Cross-Strait relation, notably in a Brookings' scholar's contribution (Bush, 2006).

2 Taiwan's commitment to the "free world" means its strategic and ideological links with the Western world and the liberalization of the economy, but did not suggest, under Chiang's leadership, any political freedom. 